\title{
BMJ Open Peripheral labour market position and risk of disability pension: a prospective population-based study
}

\author{
Klas Gustafsson, ${ }^{1}$ Gunnar Aronsson, ${ }^{2}$ Staffan Marklund, ${ }^{1}$ Anders Wikman, ${ }^{1}$ \\ Birgitta Floderus ${ }^{1}$
}

To cite: Gustafsson K, Aronsson G, Marklund S, et al. Peripheral labour market position and risk of disability pension: a prospective population-based study. BMJ Open 2014;4: e005230. doi:10.1136/ bmjopen-2014-005230

- Prepublication history for this paper is available online. To view these files please visit the journal online (http://dx.doi.org/10.1136/ bmjopen-2014-005230).

Received 10 March 2014 Revised 23 June 2014 Accepted 1 July 2014

\section{CrossMark}

\footnotetext{
${ }^{1}$ Division of Insurance Medicine, Department of Clinical Neuroscience, Karolinska Institutet, Stockholm, Sweden 2Department of Psychology, Stockholm University, Stockholm, Sweden

Correspondence to Dr Klas Gustafsson; klas.gustafsson@ki.se
}

\begin{abstract}
Objective: To investigate what impact individuals' position in a labour market core-periphery structure may have on their risk of disability pension (DP) in general and specifically on their risk of DP based on mental or musculoskeletal diagnoses.
\end{abstract}

Methods: The study comprised 45567 individuals who had been interviewed for the annual Swedish Surveys of Living Conditions (1992-2007). The medical DP diagnoses were obtained from the Swedish Social Insurance Agency (1993-2011). The assumed predictors were studied in relation to DP by Cox's proportional hazards regression. The analyses were stratified on sex and age, controlling for social background and self-reported long-standing illness at baseline.

Results: All three indicators underlying the categorisation of the core-periphery structure: employment income, work hours and unemployment, increased the risk of DP in all strata. The risk of DP tended to increase gradually the more peripheral the labour market position was. The risk estimates for DP in general and for DP based on mental diagnoses were particularly high among men aged 20-39 years.

Conclusions: The core-periphery position of individuals, representing their labour market attachment, was found to be a predictor of future DP. The association was most evident among individuals below 40 years of age with regard to DP based on mental diagnoses. This highlights the need for preventative measures that increase the participation of young people in working life.

\section{INTRODUCTION}

The sharp increase in unemployment in nearly all Western countries and the breakdown of traditional industrial structures and labour markets have led to a much more heterogeneous workforce over the past 20 years. Consequently, the traditional and simple dichotomy of the employed and unemployed has become too crude to reflect the complexity of labour markets and employment patterns in contemporary work life.

\section{Strengths and limitations of this study}

- The prospective design, number of interviews was large, and based on representative samples.

- The specific disability pension (DP)-related diagnoses were obtained from high-quality national registers.

- The follow-up period was relatively long for some individuals.

- A limitation is that the individuals' core-periphery work positions were measured at only one point in time.

Positioned in between full-time employment with a permanent work contract and longterm unemployment, there is a large group of workers in different types of precarious jobs with full-time or part-time temporary work contracts. According to some researchers, workers in these precarious types of employment comprise a new social classthe growing worldwide 'precariat'. 'In order to accommodate this complexity, recent studies on work and health have developed conceptual models that relate labour market attachment to a core-periphery structure. ${ }^{2-4}$ These studies indicate that there is a health gradient related to a peripheral position in this structure. These earlier core-peripheryhealth studies included self-employment, active in the labour market programme, other temporary employment contracts and some other forms of precarious employment. To describe the heterogeneous groups in a more comprehensive way, there are grounds for research that describe the core-periphery structure based on employment income, work hours and unemployment. An individual's place in the core-periphery structure can be seen as an alternative aspect to the traditional and often-used measure of an individual's position in the occupational hierarchy. Even among the employed, there can be large differences concerning the 
physical and psychosocial working conditions, degree of monotony and autonomy, income and the job stability provided by an occupation. ${ }^{5-7}$ Studies have shown strong correlations between hierarchical occupational position and health, certain diseases and mortality. ${ }^{8-11}$ A number of studies from the Nordic countries have reported associations between hierarchical occupational position and the risk of disability pension (DP). ${ }^{12-18}$

Individuals in the most peripheral position may end up exiting from working life by going on temporary or permanent DP because of low work capacity for health reasons. Several studies have shown that unemployment experience is associated with an increased probability of being granted a $\mathrm{DP},{ }^{19-22}$ but findings on the more intermediate positions are scarce.

In Sweden, a permanent or temporary DP could be granted to a person whose work capacity has been reduced due to medical reasons. ${ }^{23}$ Mental illness diagnoses are among the most prevalent and are the basis for one-third of new DP cases in the Organisation for Economic Co-operation and Development (OECD) countries. ${ }^{24}$ Depression-related illness contributes substantially to early exiting from the workforce. ${ }^{25}$ Several studies have shown that mental diagnosis-based DP tends to be granted at a younger age than DP based on other diagnoses. ${ }^{24}$ 26-28 A Norwegian study indicated that DP due to mental diagnoses was not only on average granted 9 years earlier than DP based on musculoskeletal diagnoses, but also it yielded the highest number of lost working years of any diagnostic group. ${ }^{26}$

Although the general trend in Sweden has been a decrease in new DP cases over the past 10 years, there has been an upward trend among young people over this period. ${ }^{23}$ In 2012, mental diagnoses accounted for more than $85 \%$ of all newly granted DPs among women and men aged 19-29 years. ${ }^{23} 29$

The present study mainly focuses on the position of individuals in the core-periphery structure of work. The aim was to investigate the potential impact that this position may have on an individual's risk of being granted DP, especially among younger men and women. A further aim was to examine not only DP in general, but also the risk of DP based on mental and musculoskeletal diagnoses, respectively.

\section{METHODS}

\section{Study group}

The study comprised 45567 men and women, 2064 years of age at the time of follow-up and born between 1928 and 1987. They were all interviewed by Statistics Sweden sometime between 1992 and 2007 in the Swedish Surveys of Living Conditions (SSLC), covering a broad range of living conditions. ${ }^{30-32}$ These annual surveys were based on year-specific random samples of the population and conducted through face-to-face interviews between 1992 and 2005 and through telephone interviews in 2006 and 2007. The annual response rates went down from $82 \%$ to $76 \%$ between the years of 1992 and 2007. If an individual happened to be included in more than 1 year's sample, only data from the earliest year were used. Additional data on the study group were gathered from the Longitudinal Integration Database for Health Insurance and Labor Market Studies (LISA; 1992-2011) and the Swedish Social Insurance Agency's database, Micro Data for Analysis of Social Insurance (MiDAS; 1993-2011).

The final cohort of 45567 individuals was reached after first eliminating those from the SSLC who had obtained a DP prior to being interviewed $(n=4128)$. During follow-up, 4376 (10.6\%) were granted a DP. The follow-up of the subcohorts started at the beginning of the year following their SSLC interview. It ended on 30 November 2011 or the year they turned 64 (old-age pension), went on DP, emigrated or died, whichever came first. Table 1 shows the characteristics of the study group, including age at interview, number of years of follow-up with SD and age when DP was granted.

\section{Measurements}

\section{Outcome variables}

Three categories of DP were used: all DP cases (information available for 1993-2011; $\mathrm{n}=4376$ ), DP based on mental diagnoses (International Classification of Disease (ICD)-10, F00-F99; available for 1994-2011; n=1183) and DP based on musculoskeletal diagnoses (ICD-10, M00-M99; available for 1994-2011; n=1693 ${ }^{33}$; table 1). Even though DPs can be full time or part time $(25 \%$, $50 \%$ or $75 \%$ ), this distinction was not taken into account in this study. The data were obtained from the MiDAS database. ${ }^{34}$

The category of all DP cases included all diagnostic groups $^{33}$ (ICD-10: categories A to Z) as well as 70 cases with unspecified diagnoses. These unspecified cases received a DP in 1993 and were mainly a result of the fact that, before 1994, individuals over 60 years of age could receive a DP partly due to labour market reasons.

\section{Exposure variable}

The exposure variable was based on data relevant to the year of interview. They were obtained from the SSLC surveys $^{31}$ and the LISA database. ${ }^{35}$ The exposure variable concerned the individual's position in the core-periphery structure and was based on the following three variables:

- Employment income. Data on personal income for the year of the SSCL interview were used to determine whether a person was to be considered employed or not. Procedures developed by Statistics Sweden to attain a good match to other labour force statistics to assess the employment status of different groups of individuals were followed. ${ }^{36}$ Three categories were defined: employed with income, not employed with some source of income (eg, sickness or unemployment benefits, but no wages from income source, one or more days) and not employed with no income. 
Table 1 Description of the study group according to sex and age at interview (1992-2007), including person years at risk, with mean and SDs, and age at disability pension (1993-2011)

\begin{tabular}{|c|c|c|c|c|c|c|c|c|}
\hline & \multicolumn{2}{|c|}{ Total number of } & \multicolumn{2}{|c|}{ No disability pension } & \multicolumn{2}{|c|}{$\begin{array}{l}\text { Disability pension } \\
(n=4376)\end{array}$} & \multicolumn{2}{|c|}{$\begin{array}{l}\text { Disability } \\
\text { pension } \\
(n=4376)\end{array}$} \\
\hline & $\begin{array}{l}\text { Men } \\
\mathbf{n}^{*}\end{array}$ & $\begin{array}{l}\text { Women } \\
n^{\star}\end{array}$ & $\begin{array}{l}\text { Men } \\
n^{*}\end{array}$ & $\begin{array}{l}\text { Women } \\
n^{\star}\end{array}$ & $\begin{array}{l}\text { Men } \\
\mathbf{n}^{\star}\end{array}$ & $\begin{array}{l}\text { Women } \\
n^{\star}\end{array}$ & $\begin{array}{l}\text { Men } \\
\text { nt }\end{array}$ & $\begin{array}{l}\text { Women } \\
\mathrm{n} \dagger\end{array}$ \\
\hline \multicolumn{9}{|l|}{ Total $n=45567$} \\
\hline \multicolumn{9}{|l|}{ Age (years) } \\
\hline $20-24$ & 3490 & 3279 & 3418 & 3168 & 72 & 111 & 13 & 12 \\
\hline $25-29$ & 2821 & 2752 & 2744 & 2612 & 77 & 140 & 31 & 48 \\
\hline $30-34$ & 2913 & 2873 & 2797 & 2617 & 116 & 256 & 59 & 116 \\
\hline 35-39 & 2716 & 2846 & 2562 & 2543 & 154 & 303 & 89 & 213 \\
\hline $40-44$ & 2691 & 2691 & 2483 & 2335 & 208 & 356 & 139 & 285 \\
\hline $45-49$ & 2725 & 2728 & 2365 & 2224 & 360 & 504 & 179 & 327 \\
\hline $50-54$ & 2460 & 2435 & 2051 & 1915 & 409 & 520 & 283 & 424 \\
\hline $55-59$ & 1824 & 1749 & 1524 & 1412 & 300 & 337 & 448 & 580 \\
\hline $60-64$ & 1295 & 1279 & 1221 & 1200 & 74 & 79 & 529 & 601 \\
\hline \multirow[t]{2}{*}{ Total } & 22935 & 22632 & 21165 & 20026 & 1770 & 2606 & 1770 & 2606 \\
\hline & Years & Years & Years & Years & Years & Years & & \\
\hline \multicolumn{9}{|l|}{ Person years at risk } \\
\hline Total $n=536737$ & 272320 & 264417 & 260244 & 246817 & 12076 & 17600 & & \\
\hline \multicolumn{9}{|l|}{ Mean number of years } \\
\hline Total mean (SD) 11.8 (5.0) & $11.9(5.0)$ & $11.7(5.0)$ & $12.3(4.8)$ & $12.3(4.8)$ & $6.8(4.1)$ & $6.8(3.9)$ & & \\
\hline
\end{tabular}

- Work hours: Individuals defined as employed may have limited work input due to having part-time employment, seasonal employment or employment only during a part of the year. Information about work hours was added to complement the employment income variable (because the income variable says nothing about working full time or part time). The variable was based on the interview data on whether the person engaged in full-time work, part-time work or had no work hours for the week preceding the SSLC interview.

- Days of unemployment: This was based on the number of registered days of unemployment benefits according to the LISA database for the year of the SSLC interview. The variable was dichotomised into no or some days (one or more days) of unemployment.

These three variables were partially different dimensions and were combined into an index measuring the individual's core-periphery position (see the classification below). These variables involve different conditions and catch up distinct conditions. Together these variables describe the employment situation in a more complete way.

1. Core: employed with income, with full-time work and no days of unemployment (reference group, prevalence $48.9 \%$ ).

2. Close to core: employed with income, with part-time work or no work hours and no days of unemployment (prevalence 21.8\%).

3. Partly core: employed with income, with full-time work and some days of unemployment (prevalence 4.7\%).
4. Middle: employed with income, with part-time work or no work hours and some days of unemployment (prevalence $5.2 \%$ ).

5. Partly peripheral: not employed with some income, with full-time work or part-time work or no work hours and no days of unemployment (prevalence $5.2 \%)$.

6. Close to peripheral: not employed with some income, with part-time work or no work hours and some days of unemployment (prevalence 5.7\%).

7. Peripheral: not employed with no income, with fulltime work or part-time work or no work hours and no days of unemployment or some days of unemployment (prevalence 8.7\%).

\section{Confounding factors}

In addition to the age at interview and the year of interview, potential confounding by social background and health status at baseline was considered. Unemployment in Sweden decreased from $8 \%$ in 1993 to $4 \%$ in 2001 and increased to $6 \%$ in 2007. Unemployment among people aged 15-24 years increased from $15 \%$ in 1995 to $23 \%$ in 2012. ${ }^{37}$ In Sweden, DP has fluctuated considerably between 1992 and 2007. Since 2004, the number of people who were granted DP has declined among people aged 30 years and older, but is still increasing among people younger than 30 years. ${ }^{23}$ The eligibility criteria have changed over time and generally in a more restrictive direction, particularly in later years. ${ }^{38}$ As a result, the year of interview was controlled for. 
Two variables for social background were included:

- Country of birth: born in Sweden with Swedish-born parents (reference); born in Sweden with one or both parents foreign born; or foreign born. The data were obtained from the SSLC surveys.

- Education: primary education ( $\leq 9$ years of education); some or all secondary education completed (1012 years); or tertiary education ( $\geq 12$ years; reference). The data were obtained from the LISA database.

Since poor health may have an effect on the exposure variables, and may independently contribute to the risk of DP, the health status of individuals at the start of follow-up was controlled for. The item measuring self-reported longstanding illness was obtained from the SSLC surveys. ${ }^{32}$

- Self-reported long-standing illness was measured by the open-ended question: "Do you have any chronic or long-term illness or health problem?" This item has been further developed by Statistics Sweden by follow-up questions and classification according to the WHO ICD-8. In this study, the summary coding of yes and no (reference) was used. Data were obtained from the SSLC surveys.

\section{Statistical analyses}

Analyses were based on Cox's proportional hazards regression and were stratified into four groups: young men (aged 20-39), young women (aged 20-39), older men (aged 40-64) and older women (aged 40-64).

First, the variables on social background conditions and self-reported long-standing illness at the time of the interview were studied in relation to the risk of DP, adjusting for age and year of interview. In this step, the three variables used as the basis for the core-periphery position were also studied.

Second, the exposure variable, core-periphery work position, was related to the risk of DP, adjusting for age at interview and year of interview, which was followed by an extended adjustment also including social background conditions and self-reported long-standing illness.

Third, two specific diagnostic groups of DP, DP based on mental and musculoskeletal diagnoses, were studied separately in accordance with the multivariate models used in the second step.

All statistical analyses were conducted with SAS, V.9.2., statistical software (SAS Institute, Inc, Cary, North

Table 2 Social background variables, health-related measures and the variables used to assess the core-periphery position (employment income, work hours, days of unemployment) in relation to risk of disability pension (DP)*

\begin{tabular}{|c|c|c|c|c|c|c|c|c|c|c|c|c|c|c|c|c|}
\hline & \multicolumn{8}{|c|}{ Ages 20-39 } & \multicolumn{8}{|c|}{ Ages 40-64 } \\
\hline & \multicolumn{4}{|c|}{ Men (n=11 940) } & \multicolumn{4}{|c|}{ Women $(n=11750)$} & \multicolumn{4}{|c|}{ Men (n=10 995) } & \multicolumn{4}{|c|}{ Women $(n=10882)$} \\
\hline & $\overline{P \dagger}$ & HR‡ & $95 \%$ & $\mathbf{C l}$ & $\mathbf{P \dagger}$ & HR‡ & $95 \%$ & $\mathrm{Cl}$ & $\mathrm{P \dagger}$ & HR‡ & $95 \%$ & $\mathrm{Cl}$ & $\mathbf{P t}$ & HR‡ & $95 \%$ & $\mathrm{Cl}$ \\
\hline \multicolumn{17}{|l|}{ Country of birth } \\
\hline $\begin{array}{l}\text { Born in Sweden with } \\
\text { Swedish-born parents }\end{array}$ & 78 & 1 & & & 76 & 1 & & & 84 & 1 & & & 84 & 1 & & \\
\hline $\begin{array}{l}\text { Born in Sweden with } \\
\text { one or both parents } \\
\text { foreign born }\end{array}$ & 10 & 1.13 & 0.80 & 1.58 & 10 & 1.47 & 1.18 & 1.83 & 4 & 0.96 & 0.70 & 1.32 & 4 & 1.06 & 0.83 & 1.35 \\
\hline Foreign born & 12 & 2.46 & 1.95 & 3.11 & 14 & 1.63 & 1.36 & 1.95 & 12 & 1.76 & 1.53 & 2.04 & 12 & 1.47 & 1.29 & 1.67 \\
\hline \multicolumn{17}{|l|}{ Education } \\
\hline Tertiary education & 28 & 1 & & & 34 & 1 & & & 29 & 1 & & & 33 & 1 & & \\
\hline Secondary education & 58 & 2.04 & 1.51 & 2.74 & 55 & 2.13 & 1.75 & 2.60 & 42 & 1.76 & 1.51 & 2.05 & 44 & 1.59 & 1.41 & 1.78 \\
\hline Primary education & 13 & 4.18 & 3.04 & 5.76 & 12 & 4.79 & 3.85 & 5.96 & 29 & 2.31 & 1.98 & 2.71 & 23 & 1.67 & 1.46 & 1.91 \\
\hline \multicolumn{17}{|c|}{ 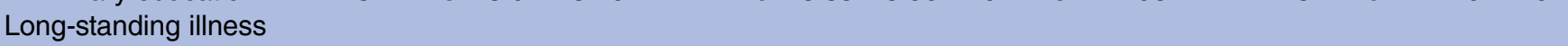 } \\
\hline No & 72 & 1 & & & 69 & 1 & & & 60 & 1 & & & 56 & 1 & & \\
\hline Yes & 28 & 3.52 & 2.90 & 4.28 & 31 & 3.75 & 3.26 & 4.31 & 41 & 3.37 & 3.01 & 3.77 & 44 & 3.30 & 2.99 & 3.64 \\
\hline \multicolumn{17}{|l|}{ Employment income } \\
\hline Employed & 77 & 1 & & & 72 & 1 & & & 88 & 1 & & & 87 & 1 & & \\
\hline Some income & 14 & 2.51 & 1.92 & 3.29 & 17 & 1.54 & 1.25 & 1.89 & 6 & 1.84 & 1.52 & 2.22 & 5 & 1.36 & 1.13 & 1.63 \\
\hline No income & 9 & 4.92 & 3.90 & 6.20 & 11 & 3.42 & 2.91 & 4.03 & 7 & 2.33 & 1.98 & 2.74 & 8 & 1.62 & 1.39 & 1.88 \\
\hline \multicolumn{17}{|l|}{ Work hours } \\
\hline Full time & 64 & 1 & & & 41 & 1 & & & 69 & 1 & & & 50 & 1 & & \\
\hline Part time & 7 & 1.83 & 1.21 & 2.76 & 29 & 1.07 & 0.89 & 1.28 & 5 & 0.84 & 0.63 & 1.11 & 31 & 1.08 & 0.97 & 1.20 \\
\hline No work hours & 30 & 2.34 & 1.91 & 2.86 & 30 & 2.06 & 1.75 & 2.42 & 26 & 1.29 & 1.15 & 1.45 & 18 & 1.21 & 1.07 & 1.37 \\
\hline \multicolumn{17}{|l|}{ Unemployment } \\
\hline No days & 73 & 1 & & & 73 & 1 & & & 87 & 1 & & & 89 & 1 & & \\
\hline $1-30$ days & 3 & 1.51 & 0.82 & 2.77 & 3 & 1.34 & 0.89 & 2.02 & 1 & 2.27 & 1.54 & 3.35 & 1 & 1.58 & 1.10 & 2.27 \\
\hline $31-180$ days & 12 & 1.63 & 1.20 & 2.22 & 13 & 1.77 & 1.45 & 2.15 & 4 & 1.98 & 1.59 & 2.45 & 4 & 1.59 & 1.30 & 1.94 \\
\hline $181-$ days & 12 & 2.86 & 2.28 & 3.58 & 10 & 2.36 & 1.97 & 2.82 & 8 & 2.08 & 1.78 & 2.43 & 6 & 1.96 & 1.68 & 2.27 \\
\hline
\end{tabular}


Carolina, USA) using the PHREG procedure. The HRs of being granted a DP with 95\% CIs were estimated.

\section{RESULTS}

The risk of DP was increased among the foreign born and among individuals with low education. The highest HRs were found among those under 40 years of age (table 2). Long-standing illness was also clearly related to risk of DP in all strata. All three indicators underlying the categorisation of core-periphery position: employment income, work hours and unemployment, increased the risk of DP in all strata. The HRs were highest among younger men (table 2 ).

When the three items were combined into the coreperipheral labour market position, the most peripheral categories (close to peripheral and peripheral) were associated with an increased risk of DP in all strata (table 3). The highest HRs in men and women aged 2039 years were among those in the most peripheral category, but even categories representing less peripheral positions showed elevated HRs. After controlling for social background conditions and self-reported longstanding illness, the associations remained but the risk estimates were on a lower level. Also, the pattern of higher HRs among the younger men and women compared to the older age groups remained in the final regression model.

For the stratified analyses of those with DP based on mental and musculoskeletal diagnoses, respectively, the statistical precision was decreased because of the reduced number of cases (table 4). However, the results showed that the peripheral and close to peripheral position had a clear impact on the risk of DP based on mental diagnoses, even after controlling for the influence of social background conditions and long-standing illness. The estimates for the most peripheral group were higher than those for the group of all DP diagnoses; this was found for all sex and age categories. Still, the highest HRs were found among individuals aged 2039 years. It could also be noted that the risk of DP based on mental diagnoses was comparatively high even among younger men close to the core.

The results for musculoskeletal diagnoses are also shown in table 4 (lower part). The impact of core-periphery position was similar to that for DP based on mental diseases, but the association was not as clear (no gradient), and based on weaker statistical precision, particularly among the younger individuals.

\section{DISCUSSION}

In this study, the focus was on the large and growing group of workers in between full-time permanent employment and lack of employment. Recent research indicates that there is a health gradient related to the individual's position in a labour market core-periphery structure. ${ }^{2-4}$ In the study, we constructed seven core-periphery categories, based on the level of employment

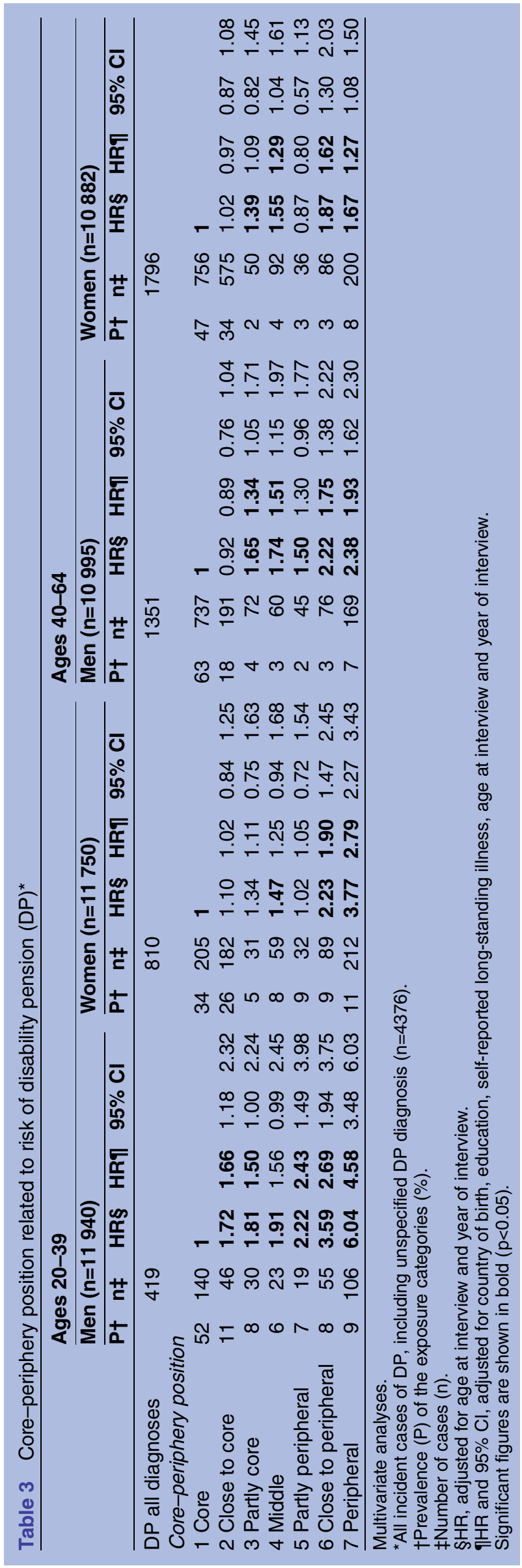


Table 4 Core-periphery position related to risk of disability pension (DP) based on mental* and musculoskeletal diagnoses ${ }^{*}$

\begin{tabular}{|c|c|c|c|c|c|c|c|c|c|c|c|c|c|c|c|c|}
\hline & \multicolumn{8}{|c|}{ Ages 20-39 } & \multicolumn{8}{|c|}{ Ages 40-64 } \\
\hline & \multicolumn{4}{|c|}{ Men } & \multicolumn{4}{|c|}{ Women } & \multicolumn{4}{|c|}{ Men } & \multicolumn{4}{|c|}{ Women } \\
\hline & $\overline{n \dagger}$ & HR‡ & $95 \%$ & & $\overline{\mathrm{n}}$ & HR‡ & $95 \%$ & & $\overline{\mathrm{n}}$ & HR‡ & $95 \%$ & $\mathrm{Cl}$ & $\overline{\mathrm{n}}$ & HR‡ & $95 \%$ & $\mathrm{Cl}$ \\
\hline $\begin{array}{l}\text { Mental DP diagnoses } \\
\text { Core-periphery position }\end{array}$ & 199 & & & & 348 & & & & 240 & & & & 396 & & & \\
\hline 1 Core & 46 & 1 & & & 78 & 1 & & & 106 & 1 & & & 173 & 1 & & \\
\hline 2 Close to core & 18 & 2.02 & 1.17 & 3.49 & 74 & 1.12 & 0.81 & 1.55 & 29 & 1.06 & 0.70 & 1.60 & 107 & 0.88 & 0.69 & 1.12 \\
\hline 3 Partly core & 16 & 2.23 & 1.24 & 4.01 & 8 & 0.80 & 0.39 & 1.66 & 18 & 2.37 & 1.43 & 3.92 & 11 & 1.18 & 0.64 & 2.17 \\
\hline 4 Middle & 10 & 2.06 & 1.03 & 4.10 & 31 & 1.75 & 1.15 & 2.67 & 13 & 2.42 & 1.35 & 4.31 & 16 & 1.16 & 0.69 & 1.93 \\
\hline 5 Partly peripheral & 8 & 2.71 & 1.25 & 5.85 & 17 & 1.29 & 0.75 & 2.23 & 10 & 2.87 & 1.48 & 5.55 & 5 & 0.53 & 0.20 & 1.44 \\
\hline 6 Close to peripheral & 32 & 4.52 & 2.81 & 7.28 & 34 & 1.95 & 1.29 & 2.94 & 20 & 3.50 & 2.16 & 5.67 & 24 & 2.26 & 1.47 & 3.49 \\
\hline 7 Peripheral & 69 & 8.88 & 5.95 & 13.26 & 106 & 4.03 & 2.94 & 5.51 & 44 & 4.08 & 2.80 & 5.94 & 60 & 2.34 & 1.71 & 3.21 \\
\hline Musculoskeletal DP diagnoses & 94 & & & & 271 & & & & 489 & & & & 839 & & & \\
\hline 1 Core & 36 & 1 & & & 75 & 1 & & & 279 & 1 & & & 335 & 1 & & \\
\hline 2 Close to core & 14 & 2.11 & 1.14 & 3.91 & 67 & 1.02 & 0.73 & 1.42 & 61 & 0.71 & 0.53 & 0.93 & 298 & 1.07 & 0.91 & 1.25 \\
\hline 3 Partly core & 9 & 1.88 & 0.90 & 3.94 & 10 & 1.09 & 0.56 & 2.13 & 31 & 1.43 & 0.98 & 2.07 & 21 & 0.94 & 0.60 & 1.46 \\
\hline 4 Middle & 5 & 1.41 & 0.55 & 3.61 & 19 & 1.09 & 0.66 & 1.81 & 11 & 0.71 & 0.38 & 1.34 & 52 & 1.55 & 1.16 & 2.08 \\
\hline 5 Partly per & 3 & - & - & - & 8 & 0.83 & 0.40 & 1.74 & 15 & 1.02 & 0.59 & 1.76 & 20 & 0.90 & 0.57 & 1.42 \\
\hline 6 Close to peripheral & 8 & 1.54 & 0.67 & 3.54 & 32 & 1.93 & 1.26 & 2.95 & 31 & 1.84 & 1.27 & 2.68 & 36 & 1.45 & 1.03 & 2.06 \\
\hline 7 Peripheral & 19 & 3.44 & 1.87 & 6.34 & 60 & 2.08 & 1.44 & 3.01 & 61 & 1.82 & 1.37 & 2.43 & 77 & 0.99 & 0.76 & 1.28 \\
\hline
\end{tabular}

Multivariate analyses.

*Mental and musculoskeletal DP diagnoses, granted 1994-2011.

†Number of cases $(n)$.

¥HR and $95 \% \mathrm{Cl}$, adjusted for country of birth, education, self-reported long-standing illness, age at interview and year of interview.

Significant figures are shown in bold $(p<0.05)$.

income, working hours and days of unemployment. These three variables were combined into an index that includes fundamental aspects of an individual's situation in working life.

The study showed that the more peripheral the work position an individual held, the higher his or her risk of DP was-with especially high HRs being found among younger individuals. After controlling for social background conditions and self-reported long-standing illness, the associations between work position and DP remained, as did the pattern of higher HRs among the younger groups as compared to the older age groups. This indicates that not only is the core-periphery structure relevant, but also it shows that other known risk factors for DP, such as immigrant status, low education and poor health, do not negate the associations. The results imply that the labour market has formed heterogeneous intermediate work positions that may increase the risk of DP, and that this pattern is especially pronounced among young people.

The results are partly in line with other recent studies examining a variety of indicators of labour market attachment and their relationship to health and disability. For example, a Finnish study found that unemployment, changes of workplace and negative factors related to the work environment were all strong risk factors for DP based on musculoskeletal diagnoses, even when social background factors were taken into account. ${ }^{22}$ Another Finnish study, which used a composite index for coreperiphery position, based on work hours, employment permanency and unemployment income, found associations with self-rated health, diagnosed diseases and depression, even among the less disadvantaged positions on the core-periphery scale. ${ }^{3}$ A Swedish study that primarily used employment contract permanency as the exposure variable similarly found that women and men in a peripheral position later reported elevated degrees of psychological distress and poor self-rated health. ${ }^{2}$

Apart from these general trends, there are also some differences between women and men that need to be further explored. The HRs for DP related to the peripheral labour market position were consistently higher for men than for women. From a gender perspective, the results indicate that a precarious labour market position seems to carry with it a higher risk of DP among men than among women and especially among younger men. Another interesting result regarding gender differences was that self-employment was a risk factor for DP among men but not among women (data not shown). This can be interpreted in several ways. First, it could be related to the fact that self-employed men and women are found in different types of businesses and also tend to have somewhat differing educational backgrounds and working conditions. Second, the labour market attachment in terms of level of income from work, working hours and unemployment is lower among men compared with women. In summary, this core-periphery perspective has been useful for obtaining a more differentiated knowledge of the working life conditions that predict DP, especially with regard to young women and men. Such knowledge is essential for developing labour market strategies for reducing the risk of DP among younger individuals. 
The Nordic countries are relatively similar with respect to the share of population granted DP. Sweden and Norway have somewhat higher shares (average $2.75 \%$ and $2.35 \%$, respectively, in 2000-2010) among the 16-39 age group than Denmark and Finland $(1.83 \%$ and $1.78 \%$, respectively), but Sweden has lower rates in older ages than the other Nordic countries. ${ }^{37}$ The Nordic countries are similar with respect to social security coverage related to DP, and the results may for this reason be comparable in a Nordic context. It is not possible to know to what degree it is possible to generalise these conditions to countries with other labour market and social security conditions.

\section{Strengths and limitations}

The major strength of the present population-based study was the prospective design. The number of interviews was large and based on representative samples with satisfactory response rates. The specific DP-related diagnoses were obtained from high-quality national registers. This indicated few missing cases over the years, as well as extensive and well-documented baseline information. This study was able to control for a number of relevant confounding factors, such as social background conditions and self-reported long-standing illness at the time of the interview. A limitation is that the individuals' work and occupational positions were measured at only one point in time and that changes in their conditions subsequent to the interview could not be taken into account. Another limitation is that we did not examine the stability of the centre-periphery structure over time.

The follow-up period was relatively long for some individuals, which meant that important changes may have taken place between the interview and being granted DP. To check the influence of the length of follow-up, we performed analyses with a follow-up period limited to 10 years. Individuals were followed to no longer than 10 years from the start of follow-up. The statistical precision was slightly lower, but the main results remained unchanged. In the current study, we had no data on the type of employment contracts or employment permanency. For further development of the core-periphery perspective, such data will be highly valuable.

\section{CONCLUSIONS}

The main finding was the tendency for more peripheral positions on the core-periphery continuum to be associated with higher risks of future DP. The association was most pronounced among young individuals and those with DP based on mental diagnoses. The results highlight the need for preventative actions that aim to expand educational opportunities and increase the participation of young men and women in working life.

Acknowledgements The authors would like to thank Maud Hagman who performed the initial computer work yielding the basic data of the study.

Contributors KG contributed to the conception, acquisition of data, design, data analysis, interpretation of the data and the drafting of the article. GA and
SM contributed to the analysis and interpretation of the data. AW contributed to the collection, analysis and interpretation of the data. BF contributed to the conception, design and acquisition and interpretation of data. GA, SM, AW and $\mathrm{BF}$ revised the article critically for important intellectual content.

Funding The study was financed by the Swedish Council for Working Life and Social Research (Dnr: 2012-0664).

\section{Competing interests None.}

\section{Patient consent Obtained.}

Ethics approval The study was approved by the The Regional Ethical Review Board in Stockholm (Dnr: 2011/1689-31/5).

Provenance and peer review Not commissioned; externally peer reviewed.

Data sharing statement No additional data are available.

Open Access This is an Open Access article distributed in accordance with the Creative Commons Attribution Non Commercial (CC BY-NC 4.0) license, which permits others to distribute, remix, adapt, build upon this work noncommercially, and license their derivative works on different terms, provided the original work is properly cited and the use is non-commercial. See: http:// creativecommons.org/licenses/by-nc/4.0/

\section{REFERENCES}

1. Standing G. The precariat: the new dangerous class. London Bloomsbury Publishing, 2011.

2. Waenerlund AK, Gustafsson PE, Virtanen $P$, et al. Is the core-periphery labour market structure related to perceived health? Findings of the Northern Swedish Cohort. BMC Public Health 2011;11:956.

3. Virtanen P, Liukkonen V, Vahtera J, et al. Health inequalities in the workforce: the labour market core-periphery structure. Int $J$ Epidemiol 2003;32:1015-21.

4. Aronsson G, Gustafsson K, Dallner M. Work environment and health in different types of temporary jobs. Eur J Work Organisational Psychol 2002;11:151-75.

5. Stover M, Pape K, Johnsen R, et al. Work environment and disability pension-an 18-year follow-up study in a Norwegian working population. Scand J Public Health 2013;41:587-96.

6. Lynch J, Kaplan G. Socioeconomic position. Social epidemiology. New York: Oxford University Press, 2000.

7. Macintyre S, McKay L, Der G, et al. Socio-economic position and health: what you observe depends on how you measure it. J Public Health Med 2003;25:288-94.

8. Lahelma E, Martikainen P, Laaksonen M, et al. Pathways between socioeconomic determinants of health. J Epidemiol Community Health 2004;58:327-32.

9. Marmot M. Status syndrome: how your social standing directly affects your health and life expectancy. London: Bloomsbury, 2004.

10. Sundquist J, Johansson SE. Indicators of socio-economic position and their relation to mortality in Sweden. Soc Sci Med 1997;45:1757-66.

11. Vagero D. Inequality in health-some theoretical and empirical problems. Soc Sci Med 1991;32:367-71.

12. Mansson NO, Rastam L, Eriksson KF, et al. Socioeconomic inequalities and disability pension in middle-aged men. Int $J$ Epidemiol 1998;27:1019-25.

13. Stattin M, Jarvholm B. Occupation, work environment, and disability pension: a prospective study of construction workers. Scand J Public Health 2005;33:84-90.

14. Haukenes I, Mykletun A, Knudsen AK, et al. Disability pension by occupational class-the impact of work-related factors: the Hordaland Health Study Cohort. BMC Public Health 2011;11:406.

15. Leinonen T, Pietilainen O, Laaksonen M, et al. Occupational social class and disability retirement among municipal employees-the contribution of health behaviors and working conditions. Scand $J$ Work Environ Health 2011;37:464-72.

16. Polvinen A, Gould R, Lahelma E, et al. Socioeconomic differences in disability retirement in Finland: the contribution of ill-health, health behaviours and working conditions. Scand J Public Health 2013;41:470-8.

17. Hannerz H, Tuchsen F, Spangenberg S, et al. Industrial differences in disability retirement rates in Denmark, 1996-2000. Int J Occup Med Environ Health 2004;17:465-71.

18. Gustafsson K, Aronsson G, Marklund S, et al. Social integration, socioeconomic conditions and type of ill health preceding disability pension in young women: a Swedish population-based study. Int $J$ Behav Med 2014;21:77-87. 
19. Helgesson M, Johansson B, Nordqvist $\mathrm{T}$, et al. Unemployment at a young age and later sickness absence, disability pension and death in native Swedes and immigrants. Eur J Public Health 2013;23:606-10.

20. Salminen K, Saarijarvi S, Raitasalo R. Depression and disability pension in Finland. Acta Psychiatr Scand 1997;95:242-3.

21. Stover M, Pape K, Johnsen R, et al. Unemployment and disability pension-an 18-year follow-up study of a 40-year-old population in a Norwegian county. BMC Public Health 2012;12:148.

22. Karkkainen S, Pitkaniemi J, Silventoinen K, et al. Disability pension due to musculoskeletal diagnoses: importance of work-related factors in a prospective cohort study of Finnish twins. Scand $J$ Work Environ Health 2013;39:343-50.

23. The Swedish Social Insurance Agency. Social insurance in figures 2013. Stockholm: The Swedish Social Insurance Agency, 2013.

24. OECD. Sickness, disability and work: breaking the barriers. $A$ synthesis of findings across OECD countries. Paris: OECD, 2010.

25. Lamberg T, Virtanen P, Vahtera J, et al. Unemployment, depressiveness and disability retirement: a follow-up study of the Finnish HeSSup population sample. Soc Psychiatry Psychiatr Epidemiol 2010;45:259-64.

26. Knudsen AK, Overland S, Hotopf M, et al. Lost working years due to mental disorders: an analysis of the Norwegian disability pension registry. PLOS ONE 2012;7:e42567.

27. Thorlacius S, Stefánsson SB, Olafsson S, et al. Increased incidence of disability due to mental and behavioural disorders in Iceland 1990-2007. J Ment Health 2010;19:176-83.

28. Brown J, Hanlon P, Turok I, et al. Mental health as a reason for claiming incapacity benefit-a comparison of national and local trends. J Public Health (Oxf) 2009;31:74-80.

29. The Swedish Social Insurance Agency. Diagnosmönster $i$ förändring -nybeviljade förtidspensioner, sjukersättningar och aktivitetsersättningar 1971-2005 [Changing Diagnostic patternsNewly Granted Disability Pensions, Sickness and Rehabilitation Allowances 1971-2005]. Försäkringskassan Redovisar 2007:3.

Stockholm: The Swedish Social Insurance Agency. [In Swedish].

30. Wikman A. Svarsprecisionen i surveyundersökningar om levnadsförhållanden. Metodproblem i individ och hushållsstatistik. Stockholm: Statistics Sweden (SCB), 1980. [In Swedish].

31. Statistics Sweden (SCB). Living conditions and inequality in Sweden-a 20-years perspective 1975-1995. Population and welfare statistics, the national Swedish survey of living conditions (SSLC/ULF). Örebro, Sweden: Statistics Sweden, 1997.

32. Wikman A. Reliability, validity and true values in surveys. Soc Indicators Res 2006;78:85-110.

33. WHO. The international statistical classification of diseases and related health problems. 10th revision (ICD-10). Geneva: WHO, 1997.

34. Statistics Sweden (SCB). Sjukpenning och rehabiliteringspenning MiDAS, version 1.02. Stockholm, Sweden: The Swedish Social Insurance Agency, 2011. [In Swedish].

35. Statistics Sweden (SCB). Integrated database for labour and market research (LISA). Labour and Education Statistics 2011:4. Stockholm: Statistics Sweden, 2011. [In Swedish].

36. Wallgren A. Registerstatistik-adminstrativa data för statistiska syften (Using adminstrative data for statistical analyses). Stockholm: Statistics Sweden, 2004. [In Swedish]

37. Nordic Council of Ministers. Nordic statistical yearbook 2013 Copenhagen: Nordic Council of Ministers, 2013.

38. Lidwall U. Termination of sickness benefits or transition to disability pension after changes in sickness insurance: a Swedish register study. Disabil Rehabil 2013;35:118-24.

39. Thorslund M, Wärneryd B. Methodological research in the Swedish surveys of living conditions. Soc Indicators Res 1985;16:77-95. 